\title{
Managing Software Enterprise Transformation: Key Influence Factors and Process Based on Services Computing
}

\author{
Guo Yifu', a , Xiang Yanping ${ }^{2, b}$ \\ ${ }^{1,2}$ College of Business, Hunan Women's University, Changsha, China, 410004 \\ ayfguo202@163.com, b1300042701@qq.com
}

Keywords: business model transformation; influence factors; software enterprise; services computing

\begin{abstract}
In the era of new economy, transformation management and dynamic management are the cores of enterprise management. Through identifying the influence factors of software enterprise transformation, including the ability to grasp opportunities for entrepreneurs, innovative spirit, as well as external financial support, consumer demand, industrial development and factors of organizational learning knowledge sharing, organizations such as vision and open mind. Structural equation modeling has built based on the survey data of 279 domestic enterprises, the study found that consumer demand, organizational learning factors and the support from the capital market play positive role in software enterprise transformation. Kingdee has been taken as an example to share excellent management experience about transformation process management.
\end{abstract}

\section{INTRODUCTION}

Business Transformation, as the name implies, deals with some renovation or make over brought in a business. Some of the definitions from literature are as follows. Prem and Mathew [1] say: "Business Transformation is a C-level leadership initiative towards corporate renewal, constituting a range of competitive strategies impacting the principal elements of a business, thus resulting in a sustainable competitive advantage." According to Vigil [2], "Business transformation is a key executive management initiative that attempts to align the operational and technological initiatives of a company more closely with its business strategy and vision." According to Enterprise Agility Inc. [3]: "Business transformation is an integrated, business-wide programme applying change management to alter the way a company does business in pursuit of a desired future state."

\section{WHAT THE KEY FACTORS THAT INFLUENCE THE SOFTWARE ENTERPAIRSE TRANSFORMATION}

Which factors and what extents that influence the software enterprise transformation (SET)? This is an important issue of concern to practitioners, ant it is concerned by theorist and entrepreneur. So research on the key influence factors and process of the software enterprise from the systematic perspective will contribute to a more profound understanding of the internal mechanism of the transformation.

\subsection{Analysis on external factors that influence software enterprise transformation}

Through expert interviews, there are many external factors that affect software enterprise transformation, such as consumer demand change, capital markets, and external cultural and technical factors.

Efficient capital markets have re-configured to optimize the allocation of resources and functions. That is, scarce capital has concentrated to innovative entrepreneurs through market channels. The securities market is a place of resource allocation, and entrepreneurs are the main allocation of resources. Therefore, it will be closely linked the market value of listed companies with the company's innovation ability, so as to inspire entrepreneurs and even really a social innovation. If the Chinese enterprises and entrepreneurs can only pursue the traditional cash flow-based business model, their short-term profit goals will continue to force them not to do investment; innovation will not be their first choice. 
Therefore, hypothesis H1a: the capital market has a positive role on software enterprise transformation.

Business model is a way of enterprises to create profits, although there are many different ways to create profit, but each company will ultimately choose a way, and the dominant way of thinking is to determine business model. A regional entrepreneurial culture will determine the organization how to filter the information, how to parse it, and to implement the corresponding actions. In general, the enterprise in a region with strong entrepreneurial culture has more likelihood to break the constraints of the existing old mode.

Therefore, hypothesis H1b: entrepreneurial culture has a positive role on software enterprise transformation.

Consumer demand structure is dynamic, changing with time and space, the industry demand changes in different segments market. In-depth exploration of these blind spots, you can find their own opportunities for businesses to create innovative business models possible. In fifteen or sixteen years ago, Nokia mobile phone industry, or doing my part of the world's oldest global market share of more than $30 \%$ of the top ten best-selling mobile phones Nokia exclusive nine. Nokia's marketing actions are as many cases of corporate research and follow. In fact, Nokia has come but so soon? In contrast to its former glory, the big brother of the mobile phone industry is indeed some desolate.

Hypothesis H1c: changes in consumer demand have a positive role on software enterprise transformation.

According to research, it is important that external knowledge sources for product and process innovation, the ability of spanning across its boundaries with external knowledge for organization will affect the organization's growth and innovation [4]. Bierly and Chakrabarti proposed that external technological learning is the main driver of the innovation process, because learning will increase new product development [5].

Hypothesis H1d: technological progress has a positive role on the BMI.

\subsection{The internal factors that impact on software enterprise transformation}

Opportunities for software enterprise transformation are result of the interaction of various forces within the economic system, unmet needs caused by changing market forces caused by nonequilibrium state, the product of unresolved problems or inefficient process. This depends on the entrepreneurs grasping the chance or take advantage of factors of production profit opportunities.

Software enterprise transformation requires entrepreneurs to fully mobilize resources outside the organization, but also requires entrepreneurs to effectively configure and use of existing resources. Of course, entrepreneurs also need to think independently, imagination, insight and ability to creative destruction for software enterprise transformation.

Hypothesis H2: The ability of entrepreneur has a positive impact on software enterprise transformation.

To draw on the experience of other scholars, entrepreneur's abilities can be classified into the ability to find opportunities, the ability to integrate resources, the ability to undertake risk and uncertainty, and made the following assumptions:

Hypothesis H2a: The ability to find opportunities has a positive impact on software enterprise transformation.

Hypothesis $\mathrm{H} 2 \mathrm{~b}$ : The ability to integrate resources has a positive impact on software enterprise transformation.

Hypothesis H2c: The ability of entrepreneurs to take risks has a positive impact on software enterprise transformation.

Another internal factor is the corporate learning ability; organizational learning can improve the efficiency and performance of software enterprise transformation and can assist effective business models to adapt to changes in the external environment. Bessant, Caffyn and Gilbert that the organization's innovation capability must be formed gradually through organizational learning in this area [6]; Zhang Jing means that its performance can be defined as the organizational learning "system transformation", that organizational learning system can be expressed as the organization 
continues to adapt to the environment. Effective organizational learning and market information processing will have more new ideas, new products and processes [7]. Xie Hongming etc had found that organizational learning has a significant positive influence on organizational innovation [8].

Software enterprise transformation is the essence of business-specific knowledge and resources through organizational learning culture, to carry out creative learning, knowledge and resources to form a creative combination of the past, and even subvert the basic assumptions and existing business models.

Hypothesis H3: organizational learning capacity has a positive impact on software enterprise transformation.

The dimensions of organizational learning and measurement variables can fixed as three dimensions: shared vision, open mind and knowledge sharing within the organization. At the same time, the following assumptions have proposed:

Hypothesis H3a: a shared vision has a positive impact on software enterprise transformation.

Hypothesis H3b: open mind has a positive impact on software enterprise transformation.

Hypothesis $\mathrm{H} 3 \mathrm{c}$ : knowledge sharing within the organization has a positive impact on software enterprise transformation.

\section{THE STUDY DESIGN}

\subsection{Data sources and validity and reliability analysis}

Survey coverage is concentrated in Hunan, Zhejiang, Guangdong, Chongqing and other places. Lasted more than two months, 343 questionnaires were returned to $46.5 \%$. 343 questionnaires were recovered; there are 279 that can be used for data analysis.

Table 1 Descriptive statistics of survey samples

\begin{tabular}{|c|c|c|c|c|c|c|c|}
\hline Project & Variable & Number & Proportion & Project & Variable & Number & Proportion \\
\hline \multirow{5}{*}{$\begin{array}{l}\text { Company } \\
\text { ages }\end{array}$} & $>40$ years & 33 & $11.90 \%$ & \multirow{3}{*}{$\begin{array}{l}\text { Ind } \\
\text { ustry }\end{array}$} & Manufacturing & 40 & $14.29 \%$ \\
\hline & $30-39$ & 47 & $16.67 \%$ & & Non-manufacturing & 133 & $47.62 \%$ \\
\hline & $20-29$ & 69 & $24.76 \%$ & & Other & 106 & $38.10 \%$ \\
\hline & $10-19$ & 66 & $23.81 \%$ & \multirow{5}{*}{$\begin{array}{l}\text { The } \\
\text { Number } \\
\text { Of } \\
\text { employee }\end{array}$} & Less than 300 & 93 & $33.33 \%$ \\
\hline & $1-9$ years & 64 & $22.86 \%$ & & $300 \sim 1000$ & 80 & $28.57 \%$ \\
\hline \multirow[t]{3}{*}{ post } & High level & 66 & $23.81 \%$ & & $1000 \sim 2000$ & 36 & $12.86 \%$ \\
\hline & The middle & 133 & $47.62 \%$ & & $2000 \sim 5000$ & 31 & $10.95 \%$ \\
\hline & Grass roots & 80 & $28.57 \%$ & & $5000 \sim 10000$ & 27 & $9.52 \%$ \\
\hline \multirow[t]{4}{*}{$\begin{array}{l}\text { Enterprise } \\
\text { Nature }\end{array}$} & State-owned & 106 & $38.10 \%$ & \multirow[t]{4}{*}{$\begin{array}{l}\text { Total } \\
\text { assets }\end{array}$} & $\begin{array}{l}10 \text { million } \sim 100 \\
\text { million }\end{array}$ & 106 & 37.99 \\
\hline & Private & 80 & $28.57 \%$ & & $\begin{array}{l}100 \text { million to } 400 \\
\text { million }\end{array}$ & 47 & $16.84 \%$ \\
\hline & Joint venture & 53 & $19.05 \%$ & & $\begin{array}{l}400 \text { million to } 1 \\
\text { billion yuan }\end{array}$ & 50 & $17.92 \%$ \\
\hline & $\begin{array}{l}\text { Foreign } \\
\text { investment }\end{array}$ & 40 & $14.29 \%$ & & $\begin{array}{l}\text { More than } \\
10 \text { billion yuan }\end{array}$ & 76 & $27.24 \%$ \\
\hline
\end{tabular}

\subsection{Hypothesis testing and analysis}

Structural equation modeling (SEM) have been used to analysis of the interaction between the variables overall relationship. Statistical software used is SPSS16.O and AMOS7.0. Also, in accordance with the preceding analysis, the use of AMOS7.0 software, draw a BMI factors of the initial structural equation model BMF1, shown in Figure 1 to illustrate the variables included in this study and the variable structure. The results include the following two aspects: First, path coefficients between the exogenous and endogenous latent variables and its statistical significance. The goodness-of-fit tests for regression models including classical parametric and autoregressive (AR) time series models are proposed. Also, in the SEM model parameter estimation using maximum likelihood estimation method, also used a variety of fit indices for models with an overall evaluation, such as degrees of freedom, chi-square value, compare goodness of fit (CFI), 
conventional goodness of fit (NFI) and root mean square error of approximation (RMSEA). Second, the test parameters is significant, the significance of evaluation parameters is reasonable, such as various path coefficients, residuals and statistically significant. This study $\mathrm{x} 2 / \mathrm{df}=4.86$, its value between 2.0 to 5.0, that the model is acceptable. BMF1 conventional goodness of fit (NFl) is 0.832 , indicating that the model fit better. CFI is 0.859 compared goodness of fit, reflecting the good fit of the model. Thus, these indicators reflect the BMF1 fitted with a good degree of fit.

On this basis, the model have been considered further amendments or optimization, the path coefficients changes between factors or are likely to significantly increase or decrease in connection.

The path of the p-value is greater than 0.45 has been deleted, the spirit of innovation - SET, organizational vision - SET and industrial development -the SET are also deleted. Through the analysis of the initial model BMF1 results, the researchers deleted the first two paths, that is, delete the industry and organizational vision. This study has been to arrive at an interim model BMF2. The researchers then delete a path, which is the spirit of innovation. This study has been to arrive at the final model BMF3. Three times the value of statistical models such as Table 2.

Table 2 The goodness of fit statistics of BMF1, BMF2, BMF3 model

\begin{tabular}{|c|c|c|c|c|c|}
\hline Model & $\begin{array}{c}\text { Degrees of } \\
\text { freedom (df) }\end{array}$ & $\begin{array}{c}\text { x 2 } \\
\text { value }\end{array}$ & $\begin{array}{c}\text { compare the } \\
\text { goodness of fit }\end{array}$ & $\begin{array}{c}\text { conventional } \\
\text { goodness of fit }\end{array}$ & RMSEA \\
\hline BMF1 & $/$ & 1699.9 & 0.859 & 0.832 & 0.1 \\
\hline BMF2 & 238 & 1101.02 & 0.905 & 0.894 & 0.096 \\
\hline BMF3 & 178 & 738.57 & 0.920 & 0.916 & 0.090 \\
\hline
\end{tabular}

Data analysis showed that, the venture capital is indeed a significant role in promoting the software enterprise transformation, the path coefficient is $0.35(\mathrm{p}<0.005)$. Consumer demand has a positive role in promoting software enterprise transformation, empirical results also support this result (path coefficient $0.62, \mathrm{p}<0.001$ ). The empirical results show that organizational learning have significant role in promoting software enterprise transformation, especially path coefficient of 0.78 between the dimension of knowledge sharing and software enterprise transformation, and pass the significance test $(\mathrm{p}<0.001)$.

The hypothesis not pass significance test is owe to the adjustment when the factor analysis reclassification. Or because too much emphasis on culture, philosophy, social atmosphere and other factors, the study design to give too much consideration.

The study found that the hypotheses between software enterprise transformation(SET) and competitive advantage, such as software enterprise transformation and value proposition, which found no significant in empirical studies, the reason have been found in retrospect feedback exchanges, the value proposition model innovation is part of the concept of innovations, on the one hand, few small businesses has made the concept of innovation, on the other hand, it may still needs time to reveal the advantages, and it more difficult for SMES to make their own innovation in the value proposition. Distinction between value realization models is not strong, and therefore it did not pass the significance detection.

\section{TAKE KINGDE AS AN EXAMPLE OF SOFTWARE ENTERPRISE TRANSFORMATION BASED SERVICES COMPUTING}

Kingdee International Software Group Company Limited (www.kingdee.com) is a listed company on the Main Board of the Hong Kong Stock Exchange (Stock Code: 00268). It is a leader of enterprise management software and internet service in China and Asia Pacific region, and a leading provider of middleware, online management and life-cycle e-commerce service provider.

When talking about how to transform, Mr. Robert $\mathrm{Xu}$ expressed that Kingdee has been conducting in-depth analysis on the demand and integration of different industries, especially for the past three years in the research and exploration of the Chinese Management Model. Summarizing and analyzing the experience of more than 1 million customers of Kingdee, Mr. Xu Shaochun summed up that transformation takes several folds. Firstly, the strategic transformation of prior 
intuitive thinking into systematic strategic philosophy, to grasp the initiative in transformation and revolution, and turning the strategic business planning to a more mature and rational plan. The other forms of transformation include transformation in research and development, operational transformation, cultural transformation and transformation of the mindset of entrepreneurs.

Table 3 steps and measures taken by Kingdee in the transformation

\begin{tabular}{|l|l|}
\hline \multicolumn{1}{|c|}{ Stages } & \multicolumn{1}{c|}{ Kingdee steps } \\
\hline Problems \& ideas & 1.shrinking profits, over capacity, financial strain \\
& 2.product paying no attention to the particular requirements of enterprises \\
& 3.cannot respond to the changes of the market environment \\
& 4.sees the trend of cloud management transformation \\
& 5.build the Chinese Management Model \\
\hline Objectives & To be the world's leading management and IT integrated solutions service provider \\
\hline Feasibility study & 1.strategic ambition \\
& 2.over 2,300 channel partners \\
& 3.Kingdee YouShang.com was rated as the 4.No. 1 market share in SAAS market. \\
& 5.innovative management \\
& 6.Excellent service provider \\
\hline Measures & Transformation takes several folds: \\
Or paths & 1.the strategic transformation of prior intuitive thinking into systematic strategic philosophy; \\
& 2.transformation in research and development; \\
& 3.operational transformation; \\
& 4.cultural transformation; \\
& 5.Transformation of the mindset of entrepreneurs. \\
\hline Execution & and \\
Monitoring & 2.Effep up our investment in management and IT integrated solution businesses \\
&
\end{tabular}

Kingdee focuses on cloud management products and services transformation, meanwhile keeps reinforcing the position both in the traditional ERP market and enterprise social network market. Kingdee are actively working with alliance partners, optimizing the values of socialized ERP, propelling business transformation with cloud and seizing opportunities in turbulent times. Kingdee will build an ecosystem jointly with its customers and partners with its cloud products of social ERP, Cloud Hub and K/3 Cloud.

Table 4 the change of the revenue model in the transformation of Kingdee

\begin{tabular}{|c|c|c|c|c|}
\hline year & Turnover (RMB'000) & $\begin{array}{c}\text { Operating profit } \\
\text { (RMB'000) }\end{array}$ & the proportion of Sales of software & $\begin{array}{c}\text { the } \\
\text { Proportion of Service }\end{array}$ \\
\hline 2010 & 1436620 & 300610 & $57 \%$ & $42 \%$ \\
\hline 2009 & 966810 & 219240 & $59 \%$ & $40 \%$ \\
\hline 2008 & 875300 & 183070 & $63 \%$ & $35 \%$ \\
\hline 2007 & 766870 & 146450 & $68 \%$ & $30 \%$ \\
\hline 2006 & 611440 & 104000 & $63 \%$ & $35 \%$ \\
\hline
\end{tabular}

\section{CONCLUSIONS}

Business transformation presumes the involvement of top management, towards a purpose of attaining substantial process improvements, financial benefits, sustainability and market leadership through a process of renewal and revitalization. This involves developing competitive strategies which could include anything from reengineering, restructuring, or reinvention.

Data analysis showed that, Consumer demand, organizational learning and the venture capital has a positive role in promoting software enterprise transformation.so we should pay attention to this factors in the process of transformation.

Chinese economy is transforming, while Chinese enterprises are also currently undergoing transformations in the strategy, operation, enterprise culture and entrepreneur etc. Most important of all, entrepreneur should transform from practical worker to thought leader, pursuing the ideological influence rather than the material success. Meanwhile leading the enterprise culture transformation, further emphasize on respecting talents and innovation of the team. 


\section{Acknowledgment}

This research was financially supported by the Human resource management, NO. 119 [2018], comprehensive reform pilot of school-level majors and Funded by Hunan Education Department Project - Research on the evolution mechanism of business model under intelligent transformation of Hunan manufacturing enterprises

\section{REFERENCES}

[1] H. Prem and G. E. Mathew, "Defining Business Transformation", May 2006. Available: http://www.wibta.com/pdf_files/defining-businesstransformation.pdf

[2] M. Vigil, "ASIL BTM Methodology", Apr.2006. Available: http://www.asilinc.com/Files/ASIL_BTM_Webinar_04_26_06v5.ppt

[3] Enterprise Agility Inc Website, "End to End business transformation". Available: http://www.enterprise agility.com/training/eebt.asp

[4] Tsai, KH and Wang, JC, External technology sourcing and innovation performance in LMT sectors: An analysis based on the Taiwanese technological innovation survey, Research Policy, 2009. 38 (3), 518-526.

[5] Bierly, PE and Chakrabarti, AK, Technological learning, strategic flexibility, and new product development in the pharmaceutical industry, IEEE Transactions on Engineering Management, 1996. 43 (4), 368-380.

[6] Bessant.J, Caffyn.J, Gilbert.J.Learing Tomanage Innovation[J].Technology Analysis and StrategicManagement, 1996, 8(1): 59-70.

[7] Zhang Jing, Relationship research on market orientation, innovation, organizational learning and organizational performance [J]. Technology Management Research, 2004 (4):49-51

[8] Xie Hongming, Han Zitian. The relationship between organizational learning and performance: is innovation the intermediate variable? - An Empirical Study of the Pearl River Delta region enterprises and Enlightenment [J]. Research management, 2005 (5): 1-10. 